\title{
MYXOMYCETES DO CANAVIAL I - LEVANTAMENTO FLORÍSTICO EM CARPINA - PERNAMBUCO
}

\author{
Eneida Jucene dos Santos' \\ Laise de Holanda Cavalcanti ${ }^{2}$
}

Recebido em 02-05-90. Aceito em 12-08-91

RESUMO $\rightarrow$ Durante um ano investigou - se a ocorrência, freqüência e constância de Myxomycetes em um canavial da Estação Experimental do PLANALSUCAR, em Carpina-PE. As observações foram efetuadas nos meses de março, junho, setembro e dezembro, correspondentes a diferentes etapas do cultivo da cana-de-açúcar. Numa área de $1.134 \mathrm{~m} 2$, observou-se um total de 40 touceiras, em cada mês de coletas, examinando-se folhas, colmos e raízes (vivos ou mortos), bem como a superfície do solo. Foram registradas oito espécies, todas pertencentes à subclasse Myxogastromycetidae: Cribraria splendens (Schr.) Pers. (Liceales); Arcyria cinerea (Bull.) Pers., A. denudata (L.) Wett. e Trichia favoginea (Batsch.) Pers. (Trichiales); Craterirum leucocephalum (Pers.) Ditmar, Physarum nucleatum Rє. , P. nutans Pers. e P. cf. pezizoideum (Jung.) Pav. \& Lag. (Physarales). No levantamento efetuado, a espécie mais freqüente foi $C$. leucocephalum $(70,4 \%)$, as demais sendo de ocorrência rara $(7,4-3,7 \%)$. Nenhuma espécie foi classificada como constante no canavial; $C$. leucocephalum foi registrada como acessória e as outras espécies como acidentais.

Palavras-chaves: Myxomycetes, canavial; Liceales; Trichiales; Physarales.

ABSTRACT - Myxomycetes from sugar-cane plantation I - Floristic Survey. Occurrence, frequence and constancy of Myxomycetes has been investigated on a sugar-cane plantation of the Experimental Station PLANALSUCAR, in Carpina, Pernambuco. The observations were carried out in March, June, September and December corresponding to differents stages of sugar-cane culture. Within an area of $1134 \mathrm{~m}^{2} / 40$ individuals were sampred at each month of collection. Their leaves, stems and roots (alive or dead) as well as soil surface were all examined. Eight species were recorded, all belonging to the subclass Myxogastromycetidae: Cribraria splendens (Schr.) Pers. (Liceales); Arcyria cinerea (Bull.) Pers., A. denudata (L.) Wett, and Tricchia favoginea (Batsch.) Pers. (Trichiales); Craterium leucocephalum (Pers.) Ditmar, Physarum nucleatum Rex, P. nutans Pers. and. P. cf. pezizoideum (Jung.) Pav. \& Lag. (Physarales). In this survey, the species most commonly encountered was $C$. leucocephalum $(70,4 \%)$, Whilst the other species had a low occurence $(7.4 \%-3.7 \%)$. None of the

1 - Mestrado em Criptógamos, Centro de Ciências Biológicas (CCB), Universidade Federal de Pernambuco (UFPE), Cidade Universitária, Recife-PE.

2 - Departamento de Botânica, CCB/UFPE, Cidade Universitária, Recife-PE 
species was classified as constant on sugar-cane plantations: C. leucocephalum (Pers.) Ditman has been registered as accessory, and the remainder as fortuitous.

Key-words: Myxomycetes; Sugar-cane; Liceales; Trichiales; Physarales.

\section{Introdução}

No Brasil, a cana-de-açúcar constitui uma das principais culturas, desenvolvendo-se em todas as regiōes, com maior produtividade nos estados próximos à costa, do Nordeste ao Sudeste (Gomes \& Lima, 1964).

Parte da zona canavieira do Estado de Pernambuco localiza-se na subzona da mata seca e compreende quatorze municípios, entre os quais encontra-se o de Carpina, onde o presidente trabalho foi realizado.

Na literatura, é registrada a presença de diversas espécies de Myxomycetes no bagaço armazenado da cana-de-açúcar (Lacey, 1974; Cavalcanti et al., 1985; Santos et al., 1986), porém para os canaviais, apenas Spegazzini (1986) refere a ocorrência destes organismos, citando quatro espécies de Physaraceae para Tucuman, na Argentina; no referido trabalho, o autor procurava descobrir o agente de uma doença da cana-de-açúcar, mas não a relacionou com os Myxomycetes encontrados. Na verdade, só ocasionalmente estes organismos prejudicam plantas cultivadas, na maioria das vezes sufocando-as por uma superprodução de corpos frutíferos (Muchovej \& Muchovej, 1987), embora em alguns casos exerçam um verdadeiro parasitismo (Erady, 1954; Pereira, 1984).

No presente trabalho, objetivou-se determinar a freqüência e constância das espécies de Myxomycetes encontradas no levantamento realizado na Estação Experimental do PLANALSUCAR, sediada no município de Carpina, iniciando uma série de pesquisas sobre o papel desses organismos nos canaviais.

\section{Material e métodos}

O levantamento foi realizado em um canavial existente na Estação Experimental do PLANALSUCÁR, em Carpina, distante $56 \mathrm{~km}$ da capital do Estado de Pernambuco; a sede municipal localiza-se a $184 \mathrm{~m}$ de altitude, nas coordenadas geográficas de $7^{\circ} 51^{\prime} 00^{\prime \prime}$ de latitude S e $35^{\circ} 15^{\prime} 30^{\prime \prime}$ de longitude W. Gr. Seu clima é AS tropical chuvoso, com verões secos, segundo a classificação climática de Köppen (Koffler et al., 1986); a temperatura média anual fica em torno de $24,5^{\circ} \mathrm{C}$ e a precipitação pluviométrica anual atinge $1.276,7 \mathrm{~mm}$ (1976-1985).

Foram efetuadas 16 excursões, nos meses de março, junho, setembro e dezembro de 1985 , sendo as coletas efetuadas na primeira e segunda quinzenas de cada mês. 
No canavial, foram examinadas touceiras vivas e restos de folhas e colmos de cana-de-açúcar caídos no solo e em diferentes estágios de decomposição. As frutificações encontradas foram coletadas juntamente com o substrato, para o qual foi anotado o órgão da planta e o seu estado (vivo ou morto); adotou-se a metodologia descrita por Cavalcanti (1974) para acondicionamento, transporte das amostras e montagem das exsicatas, as quais foram incorporadas ao herbário UFP (Departamento de Botânica, Universidade Federal de Pernambuco).

$\mathrm{Na}$ análise e identificação das espécies foram utilizados os trabalhos de Martin \& Alexopoulos (1969), Teixeira (1971), Kohlmeyer \& Kohlmeyer (1972) e Farr (1976). As medidas das microestruturas foram feitas com o auxílio de ocular micrométrica; em cada exemplar, efetuaram-se dez contagens para cada estrutura, sendo apresentada na descrição da espécie a faixa de variação encontrada, colocando-se entre parênteses os valores extremos (máximos e mínimos) das medidas só ocasionalmente observadas.

As chaves de identificação dos táxons e as descrições baseiam-se nos caracteres observados no material estudado, complementados por algumas características encontradas nas descrições originais.

A freqüência das espécies ocorrentes no canavial foi calculada por meio da seguinte fórmula:

$$
\mathrm{F}=\frac{\mathrm{n} \times 100}{\mathrm{~N}}
$$

onde:

$\mathrm{F}=$ freqüência da espécie

$\mathrm{n}=$ número de amostras da espécie

$\mathrm{N}=$ número total de amostras de Myxomycetes

Para determinar a constância das espécies utilizou-se a fórmula abaixo (Silveira Neto et al., 1976):

$\mathrm{C}=\frac{\mathrm{p} \times 100}{\mathrm{~N}}$

onde:

$\mathrm{C}=$ constância da espécie no canavial

$\mathrm{p}=$ número de excursões contendo a espécie

$\mathrm{N}=$ número total de excursões efetuadas no canavial

Conforme os percentuais atingidos as espécies foram classificadas como acidentais $(<25 \%)$, acessórias $(25-50 \%)$ ou comuns $(>50 \%)$, adotando-se o critério de Bodeheimer (1972) (apud Silveira Neto et al. 1976). 


\section{Resultados e conclusões}

No levantamento efetuado no canavial do PLANALSUCAR foram obtidas 27 amostras de Myxomycetes, pertencentes a oito diferentes espécies distribuídas em três ordens, todas citadas pela primeira vez para o Município de Carpina e em substrato de cana-de-açúcar, com exceção de Craterium leucocephalum (Pers.) Ditmar e Arcyria cinerea (Bull.) Pers.

Chave para ordens

1 - Frutificações com capilício

2 - Esporângios com incrustações calcárias, inclusive no capilício . . . . . . . . . . . Physarales (Physaraceae)

2' - Esporângios sem inscrustações calcárias . . . . . . . Trichiales (Trichiaceae) 1' - Frutificações sem capilício . . . . . . . . Liceales (Cribrariaceae)

\section{LICEALES}

Da ordem Liceales ocorre no local a família Cribrariaceae, representada por uma só espécie, do gênero Cribraria Pers., descrita a seguir:

Cribraria splendens (Schr.) Pers., Syn. Meth. Fung. 191. 1801.

Esporângios globosos, agrupados, estipitados, eretos, castanhos, $1350-4500 \mu \mathrm{m}$ alt. total, $340-530 \mu \mathrm{m}$ diâm. Hipolato pequeno, irregular, membranoso, conectando vários esporângios, castanho; pedicelo fino a espessado, altura $(1,13) 1,35-3,13(4,0) \mathrm{mm}$, base $100-250 \mu \mathrm{m}$ larg., ápice 40-125um, castanho; perídio castanho, membranoso, parcialmente evanescente, persistindo como calículo rudimentar ou reduzido; costelas grossas, unidas por membranas de cor castanha e ligadas aos nódulos achatados através de filamentos de 5 a $8 \mu \mathrm{m}$ larg., com algumas pontas livres; esporos globosos, fracamente asperulados ou espinulosos, 5,0-7,5 $\mu \mathrm{m}$ diâm., ocráceos quando em massa, hialinos sob luz transmitida.

Distribuição mundial: Europa, Ásia, América do Norte e do Sul.

Material examinado: Brasil. Pernambuco, Carpina, PLANALSUCAR: folha morta de cana-de-açúcar, E.J. Santos 130, 25/03/1985 (UFP 6513).

As características morfológicas das frutificações encontradas no canavial coincidem com as contidas na descrição de Cribraria splendens, diferindo apenas quanto ao tamanho do pedicelo. Farr (1976) comenta que esta espécie é ainda muito discutida, porque existem representantes considerados atípicos, podendo apresentar indivíduos com costelas substituindo o calículo 
e esporos ornamentados com espinhos, ambos observados nos espécimens estudados neste trabalho. Pôrto (1982) também refere pedicelos mais longos que o usual para os exemplares de Cribraria splendens que coletou numa área de mata, em Recife-PE.

Esta espécie está sendo referida pela primeira vez para a cana-de-açúcar e para o município de Carpina.

\section{TRICHIALES}

Da ordem Trichiales, ocorre no canavial estudado a família :richiaceae, com dois gêneros, distinguidos pelos seguintes caracteres:

1 - Capilício ornamentado com espirais, não ramificado . . . . . . . . . . . . . . . . . . . . . . . . . . . . . . . Trichia Hall

1' - Capilício ornamentado com dentes, verrugas, anéis e/ou meio anéis, ramificado.................. Arcyria Wigg.

O gênero Trichia Hall. está representado no local por uma espécie, descrita a seguir:

Trichia favoginea (Batsch.) Pers., Neues Mag. Bot. 1:90. 1794.

Esporângios cilíndricos, densamente agrupados, sésseis, amarelos, 430-650 $\mu \mathrm{m}$ alt., 200-530 $\mu \mathrm{m}$ diâm.; hipotalo membranoso, delicado, inconspícuo, amarelo; perídio membranoso, deiscência apical, liso, amarelo; capilício composto por elatérios com espirais destrógiras e estrias longitudinais, ápices com pontas agudas ou arredondadas, amarelos; esporo globoso, reticulado ou verrucoso, 10,0-12,5 $\mu \mathrm{m}$ diâm., amarelo em massa e amarelo pálido sob luz transmitida.

Distribuição mundial: América do Norte, América Central e américa do Sul.

Material examinado: Brasil. Pernambuco, Carpina, PLANALSUCAR: colmo de cana-de-açúcar em decomposição, E.J. Santos 172, 13/09/1985 (UFP 6565); folha morta de cana-de-açúcar, E.J. Santos 191, 11/12/1985 (UFP $6598)$.

Os espécimes identificados como pertencentes a Trichia favoginea enquadram-se perfeitamente na descrição da espécie, exceto nas dimensões dos esporos, que variam entre $10,0-12,5 \mu \mathrm{rn}$ diâm., um pouco menores que o normal $(12,9-16,0 \mu \mathrm{m})$.

Esta é a primeira vez que se refere a frutificação desta espécie sobre o colmo e a folha em decomposição da cana-de-açúcar, sendo seu primeiro re- 
gistro para o município de Carpina.

O gênero Arcyria está representado no canavial estudado por duas espécies, que podem ser separadas pelos seguintes caracteres:

1 - Esporângios cinza-pálidos, variando para amarelo, castanho-claro, ocráceo, ou prateado; frutificações ocasionalmente unidas pelos pedi-

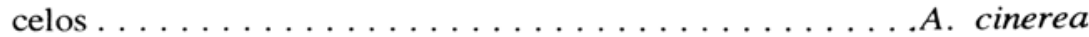

1' - Esporângios vermelhos, caindo para castanho-avermelhados ou castanhos; frutificações agrupadas ou isoladas, porém nunca unidas pelos pedicelos . . . . . . . denudata

Arcyria cinerea (Bull.) Pers., Syn. Meth. Fung. 184, 1801.

Esporângios isolados ou agrupados, algumas vezes fasciculados, estipitados, subcilíndricos ou ovóides, cinza-pálidos, $(1,17)$ 1,33-2,05mm alt. total, base $180-625 \mu \mathrm{m}$ e ápice com $90-375 \mu \mathrm{m}$ larg. hipotalo irregular, mais ou menos conspícuo, delicado, membranáceo creme; pedicelo cilíndrico, altura de $640-1075 \mu \mathrm{m}$, base $110-225 \mu \mathrm{m}$, ápice $90-180 \mu \mathrm{m}$, cinza pálido, às vezes preto na base, clareando em direção ao ápice, cheio de células semelhantes a esporos; calículo membranoso, radial, inteiramente liso ou delicadamente pontuado ou reticulado internamente, $25-275 \mu \mathrm{m}$ diâm., castanho-amarelado; perídio membranoso, parcialmente evanescente, persistindo na base formando calículo, castanho-amarelado; capilício preso à margem do calículo, reticulado, elástico porém não muito expandido, cinéreo em massa, hialino à luz transmitida, os filamentos externos apresentando espinhos, dentes ou verrugas, 2,5-7,5 $\mu \mathrm{m}$ diâm.; esporo globoso, liso, asperulado ou com poucas verrugas $(5,0) 6,0-7,5 \mu \mathrm{m}$ diâm., cinza-pálido em massa e hialino à luz transmitida.

Distribuição mundial: cosmopolita.

Material examinado: Brasil. Pernambuco, Carpina, PLANALSUCAR: colmo de cana-de-açúcar em decomposição, E.J. Santos 171, 13/09/09/1985 (UFP 6564).

Alguns dos exemplares identificados como pertencentes à Arcyria cinerea apresentam caracteres morfológicos semelhantes aos de Arcyria pomiformis (Leers) Rost., tais como a presença de dentes, espinhos e verrugas no capilício; diferiram, porém, desta última por apresentarem o interior do calículo ora liso ou delicadamente pontuado, ora finamente reticulado, caracteres considerados por Farr (1962) como essenciais para a separação das duas espécies; estes táxons são, na verdade, muito próximos, mas distintos, como evidenciaram os estudos da morfologia comparada dos corpos frutíferos efetuados pela referida autora. 
Algumas frutificações apresentavam dilatações no capilício, com 7,5-10,0 $\mu \mathrm{m}$ diâm., semelhantes às existentes em Arcyria occidentalis (Macbr,.) Lister.

Arcyria cinerea já foi mencionada para a cana-de-açúcar, frutificando sobre o colmo morto e o bagaço em fardos (Cavalcanti et al., 1985; Santos et. al., 1986), sendo esta a sua primeira referência para o município de Carpina.

Arcyria denudata (L.) Wett Verh. Zoo-Bot. Ges, Wien 35:585.1886.

Esporângios cilíndricos ou ovóides, densamente agrupados, estipitados, castanho-avermelhados quandoi recentes, castanhos quando antigos, 1,83-2,83mm alt. total, base $600-850 \mu \mathrm{m}$ diâm., ápice $425-775 \mu \mathrm{m}$ diâm., hipotalo inconspícuo, membranoso, liso, delicado, castanho-avermelhado; pedicelo delgado, estriado, castanho, altura (375) $675-1450 \mu \mathrm{m}$, base 125-275 $\mu \mathrm{m}$ larg., ápice 125-162,5 $\mu \mathrm{m}$ larg., cheio de células vesiculares semelhantes a esporos; calículo membranoso, parcialmente evanescente, castanho-avermelhado; capilício elástico, expandido, preso à margem do calículo, ornamentado com dentes ou meio anéis, os da base lisos; esporo $(5,0)$ $6,0-7,5(8,0) \mu \mathrm{m}$ diâm., liso ou com poucas verrugas, castanho-avermelhado em massa, pálido sob luz transmitida.

Distribuição mundial: cosmopolita.

Material examinado: Brasil. Pernambuco, Carpina, PLANALSUCAR: solo do canavial, E.J. Santos 15, 12/03/1985 (UFP 6563); colmo e folha de cana-de-açúcar em decomposição, E.J. Santos 17, 12/03/1985 (UFP 6505).

Os filamentos basais do capilício de alguns espécimes identificados como pertencentes à Arcyria denudata são quase lisos e sua ornamentação se assemelha bastante às referidas para Arcyria carnea (Lister) Lister; outros apresentam uma estrutura semelhante a uma pseudocolumela, formada pelo acúmulo da esporada no centro do esporângio, característica esta que náo é encontrada na descrição de Arcyria denudata.

Os demais caracteres das exsicatas examinadas enquadram-se nos descritos para Arcyria denudata, sendo esta a primeira referência desta espécie sobre colmo e folha em decomposição da cana-de-açúcar, assim como para o município de Carpina.

\section{PHYSARALES}

Da ordem Physarales, ocorre no local a família Physaraceae, representada pelos gêneros Craterium e Physarum, separados pelos seguintes carac- 
teres:

1 - Esporângios pedicelados, raramente sésseis; perídio persistindo como calículo profundo, com deiscência operculada ou apical . . . Craterium Trent.

1' - Esporângios pedicelados, sésseis ou plasmodiocarpos; perídio com deiscência irregular, sem formar calículo definido ... Physarum Pers.

O gênero Craterium está representado no canavial estudado por uma única espécie, descrita a seguir:

Craterium leucocephalum (Pers.) Ditm. ine Sturm, Deutsch. Fl. Pilze 1: 21. 1813.

Esporângios globosos a obovóides, isolados ou agrupados, estipitados, branco-acinzentados a amarelos, deiscência apical circular ou irregular, 875-1375 $\mu \mathrm{m}$ alt. total, (300) 325-700 (800) $\mu \mathrm{m}$ diâm.; hipotalo inconspícuo, circular, membranáceo, castanho claro; pedicelo $225-725 \mu \mathrm{m}$ alt., cilíndrico, castanho-avermelhado; pseudocolumela formada pela aglomeração de nódulos de cálcio no centro esporangial, branca à amarela; perídio membranáceo, calcário, persistindo na base como um calículo profundo, branco-acinzentado a amarelo no ápice, castanho na base; capilício delgado, ramificado, com expansões membranosas hialinas, com nódulos de cálcio fusiformes, angulares e arredondados, brancos, castanhos ou amarelos; esporo globoso, minutamente verrucoso ou espinhoso, preto em massa, castanho-violáceo por luz

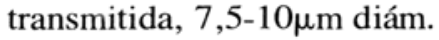

Distribuição mundial: cosmopolita.

Material examinado: Brasil. Pernambuco, Carpina, PLANALSUCAR: folha morta de cana-de-açúcar no chão, E.J. Santos O1, 11/03/1985 (UFP 6532); folha morta de cana-de-açúcar, E.J. Santos O7, 11/03/1985 (UFP 6646); folha de cana-de-açúcar em decomposição, E.J. Santos 08, 11/03/1985 (UFP 6647); folha de cana-de-açúcar senescente aderida à planta, E.J. Santos 09 , 11/03/1985 (UFP 6648); folha de cana-de-açúcar em decomposição, E.J. Santos 10, 11/03/1985 (UFP 6538); raiz de cana-de-açúcar, E. J. Santos 11, 11/03/1985 (UFP 6539); folha de cana-de-açúcar em decomposição, $E$. $J$. Santos 12, 11/03/1985 (UFP 6540); folha de cana-de-açúcar em decomposição E. J. Santos 14, 11/03/1985 (UFP 6541); folha de cana-de-açúcar em decomposição, E.J. Santos 16, 12/03/1985 (UFP 6542); folha de cana-deaçúcar em decomposição, E.J. Santos 18, 12/03/1985 (UFP 6543); folha de cana-de-açúcar em decomposição, E.J. Santos 76, 25/03/1985 (UFP 6505); folha senescente de cana-de-açúcar aderida à planta, E.J. Santos 133, 13/06/1985 (UFP 6544); folha senescente de cana-de-açúcar aderida à planta, E. J. Santos 134, 13/06/1985 (UFP 6545); folha de cana-de-açúcar em 
decomposição, E. J. Santos 137, 13/06/1985 (UFP 6546); folha senescente de cana-de-açúcar aderida à planta, E.J. Santos 158, 27/06/1985 (UFP 6547); folha senescente de cana-de-açúcar aderida à planta, E.J. Santos 187 , 27/09/1985 (UFP 6575); folha senescente de cana-de-açúcar aderida à planta, E.J. Santos 189, 27/09/1985 (UFP 6577); folha senescente de cana-deaçúcar aderida à planta, E.J. Santos 190, 27/09/1985 (UFP 6578).

Martin \& Alexopoulos (1969), assim como Farr (1976), comentam que Craterium leucocephalum apresenta grande variedade na forma dos esporângios, bem como na sua cor; quando apresenta frutificações subglobosas assemelha-se a Physarum pusillum (Berk \& Curt) Lister. As diferentes amostras estudadas consistiam de esporângios subglobosos ou ovóides, diferindo porém de Physarum pusillum pelo tamanho do pedicelo, aspecto do calículo, pseudocolumela, capilício e caracteres dos esporos, enquadrando-se na descrição de Craterium leucocephalum.

Esta espécie já foi registrada por Cavalcanti et al. (1985) para folhas mortas e bagaço da cana-de-açúcar, sendo porém referida pela primeira vez para o município de Carpina.

O gênero Physarum está representado no local por três espécies, que podem ser identificadas pelos seguintes caracteres:

1 - Esporângios deprimidos ou globosos, achatados ou umbil.icados na base ................... Physarum nutans

1' - Esporângios nunca deprimidos ou globosos, ou achatados a umbilica-

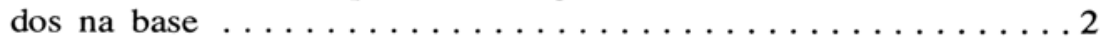

2 - Pseudocolumela presente; esporos castanhos em massa e pálidos por luz transmitida, $6,0-7,5 \mu m$ diâm. . . . . . . . . . . . . . . . . .

Physarum nucleatum

2' - Pseudocolumela ausente; esporos pretos em massa, castanho-avermelhados por luz transmitida, $10-11,0 \mu$ m diâm. . . . . . . . . . .

Physarum cf. pezizoideum

Physarum nucleatum Rex. Proc. Acad. Nat. Sc. Philadelphia 43:389. 1891

Esporângios globosos, eretos ou inclinados, agrupados, estipitados, brancos, 1,0-2,0mm alt.; hipotalo inconspícuo, circular a irregular, membranáceo, castanho; pedicelo $625-1512 \mu \mathrm{m}$, delgado, cilíndrico ou subulado, rugoso, castanho; perídio membranáceo, simples, algumas vezes persistindo na base, escamas calcárias presentes, branco; capilício denso, tubular, ramificado, com nódulos de cálcio normalmente agrupados no centro esporangial; esporo globoso, verrucoso, castanho em massa e pálido sob luz transmitida, 6,0-7,5 $\mu$ m diâmetro. 
Distribuição mundial: Nicarágua, Costa Rica, Jamaica, Porto Rico, Dominica, Trinidad, Brasil, Flórida (USA).

Material examinado: Brasil. Pernambuco, Carpina, PLANALSUCAR: folha senescente de cana-de-açúcar aderida à planta, E.J. Santos 82, 25/03/1985 (UFP 6506).

Nas amostras identificadas como Physarum nucleatum, observa-se que as frutificações apresentam esporângios com deiscência petalóide, caráter mencionado na descrição original da espécie, que porém caracteriza outras do mesmo gênero, como Physarum nutans; os corpos frutíferos apresentam nódulos de cálcio agrupados no centro esporangial, semelhantes a uma pseudocolumela. Pôrto (1982) menciona a presença de pseudocolumela nas frutificações desta espécie, das coletas que estudou, oriundas de uma reserva de mata no município do Recife-PE. O restante dos caracteres morfológicos se enquadra perfeitamente na descrição de Physarum nucleatum, sendo este o seu primeiro registro sobre folha senescente de cana-de-açúcar, bem como a primeira referência para o município de Carpina.

Physarum nutans Pers. Ann. Bot. Usteri. 15: 6.1795.

Esporângios deprimidos ou globosos, achatados ou umbilicados na base, estipitados, brancos, 1,0-1,5mm alt. total, deiscência petalóide; hipotalo inconspícuo, circular a irregular, membranáceo, castanho escuro; pedicelo $625-675 \mu \mathrm{m}$ alt., cilíndrico, delgado, afinando-se em direção ao ápice, preto na base e branco ou pálido em direção ao ápice; perídio membranáceo, persistente na base, com nódulos de cálcio; capilício tubular, delgado, ramificado dicotomicamente, anastomosado, surgindo do centro do esporângio, contendo nódulos de cálcio redondos a fusiformes; esporo globoso, asperulado,

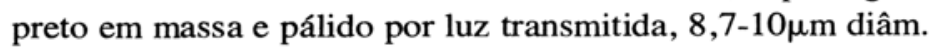

Distribuição mundial: cosmopolita.

Material examinado: Brasil. Pernambuco, Carpina, PLANALSUCAR: folha senescente de cana-de-açúcar aderida ao colmo, E.J. Santos O5, 11/03/1985 (UFP 6533).

Os espécimes identificados como Physarum nutans apresentam frutificações com a cor do pedicelo variando gradualmente desde a base, preta, clareando à medida que se distancia em direção ao ápice, tornando-se castanho-claro e chegando até o branco, assemelhando-se nesse aspecto aos comumente encontrados em $P$. nucleatum; os demais caracteres se enquadram adequadamente na descrição de Physarum nutans, que está sendo registrado 
pela primeira vez para esta espécie em folhas senescentes de cana-de-açúcar, sendo também sua primeira referência para o município de Carpina.

Physarum cf. pezizoideum (Jung.) Pav. \& Lag., Bull. Soc. Mycol. Fr. 19:87.1903.

Esporângios globosos, agrupados, estipitados, castanhos, deiscência apical irregular, 1,9-2,0mm alt., 450-525 $\mu \mathrm{m}$ diâm.; hipotalo irregular, conspícuo, membranáceo, castanho escuro; pedicelo 1,4-1,5mm alt., delgado, castanho, escuro na base e claro no ápice; perídio membranáceo, calcário, deiscência irregular; capilício tubular com expansōes membranosas, nódulos de cálcio presentes, castanhos; esporo globoso, verrucoso, preto em massa, castanho-avermelhado por luz transmitida, 10,0-11,0 $\mu$ m diâm.

Distribuição mundial: Jamaica, Porto Rico, USA e Brasil.

Material examinado: Brasil. Pernambuco, Carpina, PLANALSUCAR: colmo de cana-de-açúcar em decomposição, E.J. Santos 162, 29/06/1985 (UFP 6549).

Algumas amostras oriundas do canavial foram identificadas, com restrições, como $P$. pezizoideum, pois as frutificações se encontram muito deterioradas. Estes espécimes apresentam altura total do corpo frutífero, diâmetro dos esporângios e ornamentação dos esporos semelhantes aos de $\mathrm{Pl}_{\boldsymbol{i}}$ sarum flavicomum Berk. e de Physarum javanicum Racib. O Dr. Gerhard Gottsberger, após examinar duplicatas enviadas para confirmação da identificação, também teve dúvidas quanto à identidade do material e, considerando apenas o tamanho e coloração do pedicelo, concluiu que a exsicata talvez pertença a Physarum oblatum Macb. No conjunto, porém, os caracteres são mais próximos de Physarum pezizoideum que, após confirmação, será pela primeira vez citado como ocorrendo em colmo em decomposição de canade-açúcar, sendo também referida pela primeira vez para o município de Carpina.

$\mathrm{Na}$ Tabela 1 relacionam-se as oito espécies de Myxomycetes registradas no levantamento efetuado. Das 27 amostras obtidas, 70,3\% pertencem a Craterium leucocephalum, que apresentou uma freqüência muito maior que as demais espécies, as quais atingiram percentuais muito baixos $(3,7 \%)$, com exceção de Arcyria denudata que mostrou uma freqüência um pouco mais elevada $(7,4 \%)$.

Com relação à constância com que estes Myxomycetes ocorrem na área estudada, Craterium leucocephalum foi enquadrado na categoria de acessória $(37,5 \%)$ e as sete restantes como espécies acidentais (12,5-6,3\%). Embora não seja muito comum no canavial estudado, Craterium leucocephalum é 
referida para a cana-de-açúcar, em outros trabalhos (Cavalcanti et al., 1985; Santos et al., 1986).

Do levantamento da mixomicota efetuado no canavial do PLANALSUCAR, em Carpina, conclui-se que:

1. No local, ocorrem oito espécies de Myxomycetes, pertencentes a três diferentes ordens, cada uma representada por uma família.

2. Seis espécies de Myxomycetes são citadas pela primeira vez como ocorrentes em cana-de-açúcar: Cribraria splendens (Schr.) Pers.; Arcyria denudata (L.) Wett.; Trichia favoginea (Batsch.) Pers.; Physarum nucleatum Rex; Physarum nutans Pers. e Physarum cf. pezizoideum (Jung.) Pav. \& Lagd.

3. Os gêneros Physarum e Arcyria são os de melhor representação no local, quanto ao número de espécies.

4. Craterium leucocephalum é a espécie mais freqüente dentre as registradas no local, as demais sendo de freqüência muito rara.

5. Considerando-se a constância, nenhuma das oito espécies é comum no canavial estudado, todas sendo classificadas como acidentais, com exceção de Craterium leucocephalum, enquadrada como acessória.

6. O presente trabalho amplia a distribuição conhecida para os Myxomycetes em Pernambuco, com o registro de oito espécies como novas referências para o município de Carpina, na subzona da mata seca do Estado.

Tabela 1 - Freqüência e constância das espécies de Myxomycetes ocorrentes no canavial do PLANALSUCAR (Carpina-PE)

\begin{tabular}{|c|c|c|c|}
\hline \multirow[t]{2}{*}{ TÁXONS } & \multirow{2}{*}{$\begin{array}{c}\text { FREQÜÊNCIA } \\
(\%)\end{array}$} & \multicolumn{2}{|c|}{ CONSTÂNCIA(\%) } \\
\hline & & & \\
\hline LICEALES & & & \\
\hline Cribraria splendens (Schr.) Pers. & 3,7 & 6,3 & \\
\hline TRICHIALES & & & \\
\hline Arcyria cinerea (Bull.) Pers. & 3,7 & 6,3 & \\
\hline A. denudata (L.) Wett. & 7,4 & 6,3 & \\
\hline Trichia favoginea (Batsch.) Pers. & 3,7 & 12,5 & \\
\hline PHYSARALES & & & \\
\hline Craterium leucocephalum (Pers.)Ditm. & 70,4 & & 35,7 \\
\hline Physarum nucleatum Rex & 3,7 & 6,3 & \\
\hline P. nutans Pers. & 3,7 & 6,3 & \\
\hline P. cf. pezizoideum (Jung.)Pav. \& Lag. & 3,7 & 6,3 & \\
\hline
\end{tabular}

Total amostras: 27

$\mathrm{A}=$ acidental $<25 \%$

$\mathrm{B}=$ acessória $=25-50 \%$

$\mathrm{C}=$ comum $>50 \%$ 


\section{Referências Bibliográficas}

CAVALCANTI, L.H. 1974. Mixomicetos corticícolas do Cerrado de Emas (Pirassununga-São Paulo). Dissertação de mestrado, Universidade de São Paulo.

CAVALCANTI, L.H.; E.J. SANTOS; M.I.L. SILVA; I.M.A. PINTO, 1985. Myxomycetes em cana-de-açúcar (Saccharum officinarum L.) In: Anais da Reunião Nordestina de Botânica, 8ª , Recife.

ERADY, N.A. 1954. A new species of Stemonitis parasitic on Cereus. Kew Bulletin, 4:569-70.

FARR, M.L. 1962. Arcyria cinerea and A. pomiformis revised. Mycologia 54(5): 516-20.

FARR, M.L. 1976. Myxomycetes. Flora Neotropica. 16

GOMES, F.P. \& U.A. LIMA, 1964. A cana-de-açúcar no Mundo. In: Cultura e Adubação da Cana-de-açúcar. Capítulo 1, Instituto Brasileiro de Potassa Experimentaçōes e Pesquisas, São Paulo.

KOFFLER, N.F.; J.F.W.F. LIMA; M.F. LACERDA; J.F. SANTANA; M.A. SILVA, 1986. Caracterização edafo-climática das regiões canavieiras do Brasil: Pernambuco. IAA/PLANALSUCAR, Piracicaba.

KOHLMEYER, J. \& E. KOHLMEYER, 1972. Permanent microscopic mounts. Mycologia, 64:666-9.

LACEY, J. 1974. Moulding of sugar-cane bagasse and its prevention. Ann. App. Biol. 76:63-76.

MARTIN, G.W. \& C.J. ALEXOPOULOS, 1969. The Myxomycetes, University of Iowa Press, Iowa.

MUCHOVEJ, JJ: \& R.M.C. MUCHOVEJ, 1987. Physarum cinereum on turfgrass in Brazil. Fitopatol. bras. 12:401-3.

PEREIRA, L.V. 1984. Nova doença fúngica do guaranazeiro causada por um Myxomyceto. Fitopatol. bras. 9(1):161-3.

PÔRTO, K.C. 1982. Myxomycetes da Mata de Dois Irmãos (Recife-Pernambuco). Dissertação de Mestrado, Universidade Federal Rural de Pernambuco. Recife.

SANTOS, E.J.; L.H. CAVALCANTI; W.C. ALBUQUERQUE, 1986. Myxomycetes de Alagoas. In: Congresso Nacional de Botânica, 37ㅇ, Ouro Preto.

SILVEIRA-NETO, S.; D. NAKANO; D. BARBI; N.A.V. NOVA, 1976. Manual de Ecologia dos Insetos. Ed. Agronômica Ceres. São Carlos.

SPEGAZZINI, C. 1896. Hongos de la caña de azucar. Riv. Pathol. Vez., 3(3): 173-6.

TEIXEIRA, A.R. 1971. Gêneros de Myxomycetes. Rickia, 4:1-151 (supl.). 